\title{
The Importance of Traditional Games to Improve Children's Interpersonal Skill
}

\author{
Herlini Melianasari, Suparno \\ Yogyakart State University, Yogyakarta, Indonesia \\ e-mail: herlini.melianasari2016@student.uny.ac.id
}

\begin{abstract}
Social development is one of the capabilities possessed by early child is influenced by factor how child relationship or relation with environment. The child's personal relationships are factors that will have an impact on the child's social development. Various efforts should be made to improve children's social skills. Especially in the use of traditional games that are full of the meaning of local cultural values, in addition to stimulating early childhood social abilities. This study aims to obtain information about the importance of traditional games as a medium of stimulation of personal relationships of children aged 5-6 years. The method used in this study is a survey with a descriptive type of survey approach. Technique of data analysis in this research is descriptive analysis using mean, media, mode, percentage and grouping based on interval data. The results showed that $94 \%$ of learning in kindergarten had not used traditional games to stimulate children's personal relationship abilities. While $45 \%$ of learning activities that use traditional games and even then to stimulate the motor skills of children. Most of the lessons use the methods already contained in the curriculum and previous teaching references.
\end{abstract}

Keywords: Traditional games, ability of personal relations

\section{INTRODUCTION}

Early Childhood Education (PAUD) is the level of education that aims to prepare children physically, mentally, and emotionally social in entering the next level of education. Target PAUD is a child with age 0-6 years, this period is often called the golden age and critical period in the stage of human life, because the age range is determine the development of the next child. At this time it is very strategic to lay the basic development of all aspects of development in children include cognitive, physical, language, social emotional, self-concept, art, moral, and religious values. The early development of early childhood aims to enable children to grow and develop optimally through the fulfillment of basic health, nutrition, and emotional and intellectual development of children (Latif, et al., 2014: 3).
Education in Indonesia should not adopt other models. Education should be one of the domains in which learners can get to know more about their environment. Not exactly knowing other environments that they do not live in. This can be done by instilling love gradually and practice skills in a repetitive and continuous. In addition, reinforced with the objective of special purpose in early childhood education stated in the Regulation of the Minister of National Education No. 58 Year 2009 states that: "children are able to recognize the natural environment, social environment, the role of society, and appreciate the social and cultural diversity and able to develop the concept self, positive attitude toward learning, self control, and sense of belonging ". So it is appropriate if the natural wealth and local wisdom in culture, be one part of the learning activities that can be done by managers and educators / caregivers of Early Childhood Education (PAUD). 
Efforts that can be done so that children grow and develop optimally is to provide an environment that can stimulate child development. Educational institutions as one of the environments that can provide the needs of children are expected to provide a learning experience in accordance with everyday experience while developing aspects of cognitive development, social, emotional, and physical. In accordance with the opinion of Hasan (2009: 15), the implementation of early childhood focuses on the basic laying toward growth and physical development and intelligence, thinking power, creativity, emotion, spiritual, language / communication and social. The entire learning experience the child gained in the learning process. In early childhood education should focus on activities that are interesting, fun and not pushy. for the learning activities to be interesting must be formulated into the game. So there is learning in the game and the child does not feel forced to be more interesting not boring. As the opinion of Latif, et al. (2014: 7), play is the need and activity that is done at an early age, because by playing the child acquires a learning experience that contains aspects of cognitive, language, social emotional and physical. Playing also stimulates the child to develop in general, both developing thinking, emotionally, and socially.

Traditional games as one of the play activities can be used as a learning resource to meet the needs of children in developing the potential include cognitive, language, emotional, social and physical motor. Playing a traditional game aims not only to develop physical activity but more to the cognitive and social abilities. As the result of Fauzi's research (2016) Cim-ciman game not only able to train the development of motor, language, cognitive, social and moral but also as media to instill and form cultural values and build character of child. If each learning activity can incorporate every traditional game into the core curriculum not only becomes an attachment, the benefits will be enormous. From the point of view of education, the potential of children is growing very rapidly because the learning activities presented are able to holistically develop aspects of child development.

In addition to meeting the needs of young children in developing potential, incorporating traditional games in learning activities is an effort to preserve the culture. As we know the traditional game as one of the nation's cultural wealth from time to time began to be abandoned and forgotten by the community. It can be seen from the type of game chosen, children tend to prefer to play with the game smelled of technology, games from mobile phones and internet. The child who prefers the modern game will grow into a more selfish child who is accustomed to his own world because he is no longer doing cooperative activities, learning to tolerate, understand each other, forgive, coarse motor movements and balance in a game (Susilo, 2016).

The modern game is considered more challenging to children than traditional games that are considered outdated. Although there are some people who argue that modern games can develop the cognitive abilities of children because in the game there are activities of strategy preparation. But that is not entirely true, as Amini's (2014: 96) study concludes that children who are addicted to online game play have an effect on their learning achievement.

Reliving traditional games in child activities is not easy in this modernization era. Every layer of society must first understand its role so that people can do various ways in accordance with the field that they do to revive the traditional game. One of the efforts undertaken by the City Government of Pekalongan to revive the traditional game by celebrating National Batik Day. In the celebration dozens of students participated in playing traditional games such as Gobak Sodor, Egrang, Bakiak Panjang, Dacon, Nekeran, and Jump Rope. In each game it is seen that not all students are good at practicing the game (Setiadi, 2015).

Returning the traditional game back into daily activity can not be done only by celebrating once a year, it takes activities that routine and continuity to permianan traditional back as before. It is still clearly remembered by the community in the $90 \mathrm{~s}$, many children perform traditional game activities in the yard every afternoon together with their friends. Even during school holidays the child prefers to play traditional games all day until the time is forgotten.

The research study conducted by Yucel Gelisli (2015) gives the final result that research, found that the game contributes to the emotional development, language, cognitive and social fields of children and for their self-care to a great extent. In addition Avanti Vera Risti Pramudyani (2017) argues that traditional games can be input into the curriculum. Traditional games can be integrated into the curriculum to improve the learning of a higher quality and can improve the development of early 
childhood to the fullest. As for research from Dian Wahyuningsih (2015) which says that involving local wisdom in learning model can stimulate social ability of early child. The research of Dwi Imam Efendi and Avanti Vera Risti gives similarities to the research that is in the traditional game. In addition, with research Dian Wahyuningsih have similarities in social skills based on local wisdom.

Although, this study has differences in the study of personal relationships that are included in aspects of social development. In previous studies traditional games focus more on the physical aspects of motor, but in this study to identify social aspects that focus on personal relationships. This research becomes important because the ability of personal relations becomes the main factor to support the social ability of children. When a child's wellformed social development will impact on other developments such as language. of the child's personal relations ability will enrich the language skills. In addition, cognitive and motor skills have increased. So the ability of personal relationships becomes an important thing to be studied with various methods applied in early childhood learning.

\section{METHOD}

This research uses quantitative approach of survey type. Research subjects were kindergarten teachers at Temuwuh Lor. The number of children tamna for children aged 5-6 years of 3 kindergarten with total teachers kesuluruhan 15. Samples taken using purposive sampling technique. Because this study aims to rural areas regarding the importance of traditional games. Samples taken were 15 respondents who joined in groups of children aged 5-6 years in Kindergarten B.

To obtain the data as desired, in this study used questionnaires and interviews. This instrument is chosen with the consideration that the questionnaire can capture information on a large scale with a relatively fast time. Questionnaires are used to find out whether teachers use traditional games in learning. Observation to see traditional games in stimulating children's social skills.

The data analysis technique that the researcher use is descriptive analysis using mean, median, mode, percentage, and pengelompakan based on interval data. The data is then exposed / described more details in the form of tables.

\section{RESULT AND DISCUSSION}

\subsection{Result}

In the results and this discussion presented the data utilization of traditional games in learning in kindergarten Aba Temuwuh Lor. But to know the characteristics of resource in this research, it will be discussed first some data survey results about the characteristics of resource persons in this study. The existence of exposure characteristics of resource persons in this study is expected to provide more meaningful intact on the data in this study.

Based on the data collection that has been done using questionnaire, it is known that the resource in this research is educators who are aged over 30 years. If described in more detail, then there are two divisions, $71 \%$ of resource persons between 31 to 50 years and $19 \%$ of resource persons aged over 50 years. None of the sources are under the age of 30 .

When viewed from the qualifications of education there are some interesting data. Of all teachers, not all have taken the bachelor level, there are some teachers who still have the background of senior high school or equivalent. Teachers who are still qualified for senior high school or equivalent are $13 \%$. This can be interpreted that there are still teachers in PAUD who have not qualified undergraduate. Teachers who have taken bachelor degree education are $84 \%$. From teachers who have qualified undergraduate education, it does not all come from undergraduate education of PAUD teachers. Not a few teachers who incidentally is PAUD educators come from scholars who are not linear with the field that they tekuni today. The data states that only $35 \%$ of teachers are graduated from the education of PAUD educators, the rest is obtained from scholars outside PG PAUD.

Table 1 Teacher Identity

\begin{tabular}{llc}
\hline & Characteristics & Percentage \\
\hline \multirow{2}{*}{ Teacher's age } & Below 30 th & $0 \%$ \\
& Between 31 sd 50 th Above & $5071 \%$ \\
& years High school & $19 \%$ \\
Education & Strata 1 & $13 \%$ \\
Qualification & Strata 2 & $84 \%$ \\
Education & Bachelor of PAUD & $0 \%$ \\
suitability & Not an early childhood scholar & $65 \%$ \\
Develop a Model & In accordance with the 75\% & \\
& Curriculum Guide & $25 \%$ \\
\hline
\end{tabular}


Furthermore, the exposure of data about the use of traditional games in learning in early childhood. The data obtained shows that $100 \%$ of respondents have used traditional games in PAUD learning activities. However, not all respondents have used traditional games in the learning process. If devoted in the context of learning, only $35 \%$ of respondents have ever used traditional games in learning. Moreover, $65 \%$ of respondents use traditional games outside of learning. This data indicates that more respondents are using traditional games outside of learning when compared to being used during lessons and included in the RPPH (Daily Learning Implementation Plan).

Regarding the benefits to be gained from traditional games, all (100\%) of respondents agree that traditional games bring positive benefits to children. More specifically, all respondents also agree that traditional games can affect the child's developmental process. Especially social development because in play the child will use his ability to establish relationships for the game can run well. Some developmental processes are believed by more than $80 \%$ of teachers agree that traditional games can stimulate children's social skills. And $20 \%$ of teachers think traditional games can simulate other developments such as cognitive, linguistic and motor depending on the teacher's ability to process the game.

Based on data stating that all respondents have used traditional games, the majority of respondents have only used 6 types of traditional games in their activities. The data says that $48 \%$ of respondents only ever use 2 types of traditional games. $48 \%$ of respondents stated that they used 3 to 6 kinds of traditional games in the early childhood learning process. Moreover, only 3\% of teachers claim to have used 7 to 10 traditional games in the learning process. There are ten traditional games mentioned by the teacher have been used in the learning process in early childhood both in learning and outside of learning. The ten traditional games are: Round Umpet, Jaranan, Congklak / Dakon, Clog / Teklek, Running Tempurung / Egrang Bathok, Cublakcublak Suweng, Mushroom, Kentungan, Dragon Snake and Sluku-sluku Bathok. The five most common traditional games used by respondents are: a) Parcel Umpet, b) Cublak-cublak suweng, c) Mushrooms, and d) Jaranan.
Table 2. Traditional games and learning

\begin{tabular}{|c|c|c|c|}
\hline & The use of traditi & al games & Percentage \\
\hline \multirow[t]{2}{*}{1.} & Ever use & Ever & $100 \%$ \\
\hline & $\begin{array}{l}\text { The traditional } \\
\text { game inside } \\
\text { activities in } \\
\text { kindergarten }\end{array}$ & Not yet & $0 \%$ \\
\hline \multirow[b]{2}{*}{2.} & & In & $35 \%$ \\
\hline & $\begin{array}{l}\text { Traditional } \\
\text { game usage } \\
\text { time }\end{array}$ & $\begin{array}{l}\text { learning } \\
\text { Outside } \\
\text { learning }\end{array}$ & $65 \%$ \\
\hline \multirow{3}{*}{3.} & \multirow{3}{*}{$\begin{array}{l}\text { The great } \\
\text { variety of } \\
\text { traditional } \\
\text { games ever } \\
\text { used }\end{array}$} & $\begin{array}{c}<2 \text { types of } \\
\text { games }\end{array}$ & $48 \%$ \\
\hline & & $\begin{array}{c}3 \text { to } 6 \text { types } \\
\text { game } 7 \text { to } \\
10 \text { types }\end{array}$ & $\begin{array}{c}65 \% \\
3 \%\end{array}$ \\
\hline & & $\begin{array}{l}\text { game> } 10 \\
\text { types of } \\
\text { games }\end{array}$ & $0 \%$ \\
\hline \multirow{5}{*}{4.} & \multirow{5}{*}{$\begin{array}{l}\text { Traditional type } \\
\text { of game } \\
\text { the most often } \\
\text { selection }\end{array}$} & $\begin{array}{l}\text { a. Hide and } \\
\text { seek }\end{array}$ & $45 \%$ \\
\hline & & $\begin{array}{l}\text { b. Cublak } \\
\text { suweng }\end{array}$ & $42 \%$ \\
\hline & & c. Moldy & $39 \%$ \\
\hline & & d. Jaranan & $35 \%$ \\
\hline & & e. Game & $>35 \%$ \\
\hline
\end{tabular}

As based on interviews about traditional games ever undertaken by teachers agree that most traditional games can be used as a medium of stimulation of personal relationships of early childhood. Furthermore there are also other games that can stimulate the aspects of cognitive development, language, and motor. The game specifications obtained from interviews based on aspects of development obtained by early childhood, as follows:

a. Plot Umpet: the main aspects developed are child's motor but also must be supported by good personal relations skills. Because children are required to use a good relationship between friends so as not to tell each other the hiding location of each child.

b. Jaranan: the main development is the motor further requires the ability of personal relationships such as establishing a harmonious relationship to happen cohesion between friends when doing jaranan motion.

c. Congklak / Dakon: cognitive becomes the most important aspect, it takes the ability of personal relationships to trust each other not to cheat and be responsible. 
d. Sundanese manda: Motorik needed further personal relationships skills are used to establish relationships in waiting for turn and good patience.

e. Running Tempurung / Egrang Bathok: Motoric preferred, personal relationships are used as a relationship to support each other does not collide.

f. Cublakcublak Suweng: social skills are prioritized and further supported by personal relationships for mutual trust and non-cheating.

g. Mushrooms: social skills will be further supported by personal relationships for mutual trust and non-cheating

h. Stilts: motor is preferred, personal relationships are used as relationships to support each other not to collide.

i. Dragon Snake: It takes social ability to build good relationships in order for the game to run with fun.

j. Sluku-sluku Bathok: motor preferred to be the supporting aspect is the ability of personal relationships in singing the agreed song.

\subsection{Discussion}

In accordance with the objectives and the formulation of research problems, the data have been obtained can be used to answer some formulation problems that have been formulated, among others:

First, based on the research data says that all respondents have used traditional games, but not all done in learning. From the respondents' information, the use of traditional games in the learning process is still relatively rare $(35 \%)$ compared to those who use it outside of learning $(65 \%)$. This data indicates two things at once. Initial indicators suggest that respondents are aware of the importance of traditional games in learning. This is corroborated by data stating that all respondents are convinced of the positive benefits that exist in traditional games and those benefits are related to the child's developmental process. Especially personal relationships. This belief is similar to the result of Pamungkas (2015: 8) research which stated that playing estika motion through traditional game can positively influence on early childhood moral development.

Another indicator of traditional game usage data is about the low data use of traditional games in learning. These conditions indicate the limitations of comprehensive reference for respondents to use traditional games as learning resources in learning not just outside of learning. This situation proves that the teacher's lack of understanding about traditional games can be involved in learning so that training is needed to provide insight into the traditional game-based learning model. From a wide range of traditional games that there are only 10 done by teachers, it even done only outside of learning is not in the process of learning.

All respondents have a positive view of the traditional game, particularly in relation to the child's developmental process. In another context, today the child is being haunted by a digital media addiction that keeps children away from social activities. So that the use of traditional games can be as well as intermediary children to improve children's social activities. Traditional games such as Bekelan, Dakon, Engkelek, Suweng Cublak, Bakiyak Panjang, and Compass marbles when applied in the learning activities can develop the ability of children in counting, thinking focus, sociable, communicating, socializing, and cooperating. The association of traditional games with improved early childhood social skills has been proven by several researchers. The research results Perdani (2013: 339) mentioned that the traditional games applied in teaching experiments can hone and able to provide good stimulus to PAUD students in the aspect of togetherness, sharing, communicating, active participation and adaptability with peers.

The results of this study also show a positive mindset of educators about traditional games. This condition can be drawn from the response of all respondents $(100 \%)$ who acknowledged the positive benefits to the child's potential development. As a conclusion taken by Andriani (2012: 135), that one way to increase the potential of children at an early age is with traditional games because many elements of benefit and preparation for children living social life. Positive condition of respondents about this traditional game will facilitate the process of diffusion of innovations important traditional games as a medium of stimulation of personal relationships in kindergarten. From the results of conclusions in this study at once can be an early stage for researchers to develop the ability of personal relationships based on traditional games in the learning process.

Both of the interview results obtained an explanation of the details of traditional games that are usually done by the teacher. Of the ten 
traditional games overall stimulate the ability of the child's personal relationships. Because in the traditional game indirectly children are required to establish good relationships with peers, respect each other, understanding, patience and responsibility. This is also supported by research conducted by A. Nidha Eka Restuti Munawir, explaining that from the acquisition data of traditional game model development results to improve the ability of early childhood personal relationships, which is seen improvement of children ability after game activity, besides all traditional games effective in improving the ability of personal relationships. and looking at the values and ranges between before and after the play, it is seen that the most effective game in improving personal relationship skills is this game can be seen from the acquisition of the value before and after the game, with a value range of 40.3. The next game is akbombo-bombo with the acquisition of range values before and after game 38,1, and the next game is gallak-gallak with the acquisition of range values before and after game 30,9.

\section{CONCLUSION}

The conclusions of this study are as follows:

a. The whole aspect of child development can be supported by involving traditional games in learning, which is primarily the ability of personal relationships included in the child's social development aspect to be stimulated through traditional games applied through learning.

b. It is important to apply traditional children's games, because the cultural values and identity contained in the game are already being forgotten by children today. So it needs to be applied in the learning.

c. Teachers need to develop a free learning model that involves traditional games then supported by parents, community and government.

d. Involving parents with workshop activities, seminars and conferences on traditional games that provide benefits to aspects of child development.

Further research needs to examine the game that fits the stage of child development.

\section{REFERENCES}

[1] Amini,S. http://repo.unand.ac.id/355A/reposit Retrieved July 2018

[2] Avanti Vera Risti Pramudyani, M. and Ragil Kurniawan, " Integrated Traditional Game Holistic Curriculum In PAUD Yogyakarta" Vol 10 No. 2 September (20 17) .

[3] Dian Wahyuningsih . " Implementation of Local Wisdom through Bcct Model for the Development of Early Childhood Social Skills " Vol 2 No. 1 March (2015)

[4] Fauzi., " Formation of Child Character Through Game Cim-ciman " Faculty of Tarbiyah IAIN Purwokerto. (2016)

[5] Hasan, M. (2009). Early childhood education programs. Yogyakarta: Diva Press.

[6] Latif, M., Zukhaira, Zubaidah, R., \& Affandi, M. (2014). Oriented Education of Early Childhood Education. Theory and Applications (2 ed.). Jakarta: Kencana: Prenada Group.

[7] Setiadi, T. http://berita.suaramerdeka.com/per Retrived July 2018

[8] Susilo: E. B , http: // permainan.tradisional.telah.dilupakan ki.fi/data/ Retrieved July 2018 .

[9] Yucel Gelisli a [1] and Elcin Yazici b : Procedia - Social and Behavioral Sciences , " A Study into Traditional Child Games Played In Konya Region In Terms Of Development Fields of Children 1971859 - 1865 (2015). 